\title{
An In-Gel Assay for Protein Tyrosine Phosphatase Activity: Detection of Widespread Distribution in Cells and Tissues
}

\author{
Keith Burridge and Andrew Nelson \\ Department of Cell Biology and Anatomy, University of North Carolina at Chapel Hill, Chapel Hill, North Carolina 27599
}

Received J une 5, 1995

A method is described for the detection of protein tyrosine phosphatase activity in sodium dodecyl sulfate-polyacrylamide gels. A radiolabeled substrate, ${ }^{32} \mathrm{P}$-labeled poly(glutamic acid-tyrosine) (random copolymer) is incorporated into gels prior to polymerization. Following electrophoresis, the sodium dodecyl sulfate is removed; the proteins are fully denatured by soaking gels in $6 \mathrm{~m}$ guanidine hydrochloride and then renatured by incubation in buffers containing $0.04 \%$ Tween $\mathbf{4 0}$ and high concentrations of reducing agents. Protein tyrosine phosphatase activity is detected in autoradiographs of dried gels as regions from which the ${ }^{32} \mathrm{P}$ has been selectively removed. Electrophoresis of known cytoplasmic protein tyrosine phosphatases indicates activity at the predicted molecular weights. As little as $10 \mathrm{pg}$ of some cytoplasmic phosphatases is detectable. However, transmembrane tyrosine phosphatases, such as CD45, are detected only at very high protein loadings in this assay. Electrophoresis of whole cell lysates indicates multiple bands of tyrosine phosphatase activity, some of which comigrate with known cytoplasmic protein tyrosine phosphatases. The activity is inhibited by sodium orthovanadate or the omission of reducing agents during the renaturation process. The assay has been used to analyze embryonic and adult tissues, as well as whole cell lysates. A similar profile of bands of tyrosine phosphatase activity is seen with many different cells and tissues. However, some that are highly differentiated, such as adult skeletal muscle, erythrocytes, or sperm, reveal either a reduced level of tyrosine phosphatase activity or a simplified profile of bands. $\odot 1995$ Academic Press, Inc.

The phosphorylation of tyrosine residues in proteins is a common and critical event in many cell signaling pathways involved in growth, differentiation, and the response of cells to extrinsic factors $(1,2)$. Tyrosine phosphorylation is regulated by both protein tyrosine kinases and protein tyrosine phosphatases (PTPases). ${ }^{1}$ Originally it was considered that PTPases function simply to remove phosphates from tyrosine residues, thereby restoring substrate proteins to their resting states. During the past few years, however, it has become apparent that PTPases may participate more actively in signaling pathways. In many cases the activity of tyrosine kinases is itself regulated by tyrosine phosphorylation, and so the removal of phosphates from tyrosine kinases by PTPases may lead to either their activation or inhibition. During the past few years a large number of PTPases have been isolated, cloned, and sequenced (3-5). Two distinct groups of PTPases have been identified. One group is transmembrane proteins, with extracellular domains that resemble receptors, although ligands for these have generally not been identified. The other group of PTPases is cytoplasmic. Many of these reveal domains, such as src homology 2 (SH2) domains, suggestive of complex interactions or modes of regulation (3-5). In addition, within this latter category there is a subgroup of phosphatases that demonstrates dual specificity for both phosphotyrosine and phosphoserine or phosphothreonine (3-5). The first members of this subgroup were viral proteins, but several cellular dual specificity phosphatases that act on proteins such as MAP kinase have now been identified (3-5).

While contemplating the increasing number of identified PTPases and their apparent complexity, it occurred to us that it would be useful to be able to identify specific PTPases in crude mixtures such as whole cell Iysates. This could be done with antibodies against particular PTPases, but for many of the recently identified PTPases antibodies are not available. In addition, novel PTPases would not be detected by this approach. An alternative strategy would be to use an "in-gel"

\footnotetext{
${ }^{1}$ Abbreviations used: PTPases, protein tyrosine phosphatases; SH2, src homology 2; VH6, vaccinia human homolog 6; HUVEC, human umbilical vein endothelial cells; REF, rat embryo fibroblasts.
} 
assay, in which PTPase activity is detected directly in SDS polyacrylamide gels. I n-gel assays have been used to identify numerous different enzymatic activities, most readily in nondenaturing gels (6). However, some enzymes can be renatured and assayed after SDSPAGE, which has the advantage of indicating the relative molecular mass of the catalytic subunit. This type of assay has been used for many years in the study of proteases (7-12), where it is often referred to as "zymography" $(11,12)$. It has also been used with some protein kinases such as calmodulin-dependent protein kinase II (13) and mitogen-activated protein kinases (14). In this paper an in-gel assay for detecting PTPases resolved in SDS - polyacrylamide gels is devel oped. The assay is used to analyze the distribution of PTPases in different tissues and cell types.

\section{MATERIALS AND METHODS}

Materials. All materials were obtained from Sigma Chemical Co. (St. Louis, MO), unless otherwise stated. Poly(glutamic acid-tyrosine) random copolymer (4:1 ratio) (poly(glu:tyr)) was from Sigma (Catalog No. P0275, molecular weight 20,000-50,000). Purified PTPases, PTP1, the Yersinia PTPase and a dual specificity PTPase, VH6 (vaccinia human homolog 6), were the generous gifts of Drs. J ack Dixon and Daniel Lohse (Univ. of Michigan, Ann Arbor, MI).

Source of tissues and cells. Chicken embryos were obtained from fertile eggs that were purchased from North Carolina State University (Raleigh, NC). Tissues from 5-week-old chickens were kindly provided by Dr. Quresh (NC State University, Raleigh, NC). Tissues from freshly slaughtered adult chickens were purchased from Golden Poultry (Sanford, NC). Purified human erythrocytes and blood platelets were a gift of the laboratory of Dr. G. White (Univ. of NC, Chapel Hill, NC). Purified monocytes and peripheral blood lymphocytes were kindly provided by the lab of Dr. S. Haskill (Univ. of NC, Chapel Hill, NC). Washed human sperm samples were a gift of Dr. P. Saling (Duke University, Durham, NC). Human umbilical vein endothelial cells (HUVEC) were kindly provided by Dr. L. Romer and Ms. N. Maclean. MCF 10 cells were the gift of Dr. M. Kinch (Univ. of NC Chapel Hill, NC). NIH3T3 cells, rat embryo fibroblasts (REF52), src-transformed rat fibroblasts (RR 1022), and Hela cells were grown in Dulbecco's modified Eagle's medium with $10 \%$ fetal bovine serum. Raji cells (a human B cell lymphoma) were grown in RPMI medium supplemented with $10 \%$ fetal bovine serum.

Preparation of samples for gels. Cell samples were prepared for electrophoresis by first washing the cells twice in serum-free medium and then dissolving the cells directly by scraping in SDS-gel sample buffer (15). The samples were quickly boiled for at least $2 \mathrm{~min}$ and the samples passed through a 26-gauge syringe needle multiple times to shear DNA. Tissue samples were prepared by homogenizing the tissues in $20 \mathrm{~mm}$ EGTA, pH 8.0, containing $25 \mu \mathrm{g} / \mathrm{ml}$ aprotinin and 25 $\mu \mathrm{g} / \mathrm{ml}$ leupeptin. Following homogenization, the samples were mixed with an equal volume of SDS - gel sample buffer and boiled. To determine the protein concentration in different tissue or cell samples, 100- $\mu$ l aliquots of samples were mixed with an equal volume of $20 \%$ trichloracetic acid and incubated on ice for 30 min. The precipitated protein was collected by centrifugation at $12,000 \mathrm{~g}$ for $10 \mathrm{~min}$ and then dissolved in 100 $\mu \mathrm{l}$ of $0.125 \mathrm{M} \mathrm{NaOH}$. Aliquots of this were used to measure the protein concentration using the Pierce Company's modified Bradford assay (Pierce Co., Rockford, IL).

Immunoprecipitation. A monod onal antibody against PTP1D was purchased from Transduction Laboratories (Kentucky). A monoclonal antibody against PTP1B was the gift of Dr. N. Tonks. For immunoprecipitation with these antibodies, cells in 10-cm culture dishes were washed with serum-free medium and then lysed and scraped in $0.5 \mathrm{ml}$ ice-cold lysis buffer $(150 \mathrm{mM} \mathrm{NaCl}$, $50 \mathrm{~mm}$ Tris- $\mathrm{Cl}$, pH 7.6, 1 mm EDTA, 1 mM EGTA, 1 $\mathrm{mm} \mathrm{Na}$ ortho-vanadate, $0.2 \%$ Triton $\mathrm{X}-100,0.1 \%$ deoxycholate, $25 \mu \mathrm{g} / \mathrm{ml}$ leupeptin, $25 \mu \mathrm{g} / \mathrm{ml}$ aprotinin, $0.1 \mathrm{~mm}$ PMSF , $0.1 \% \mathrm{NaN}_{3}$ ). The cell Iysates were clarified for $10 \mathrm{~min}$ in a microfuge and the supernatants were incubated with $2 \mu \mathrm{l}$ of antibodies and $100 \mu \mathrm{l}$ of $10 \%$ protein A - Sepharose (Sigma) to which rabbit anti-mouse IgG had been conjugated. The lysates were incubated with rotation for between 1.5 and $4 \mathrm{~h}$ at $4^{\circ} \mathrm{C}$. After pelleting in a microfuge for $30 \mathrm{~s}$, the immunoprecipitates were washed three to four times in Iysis buffer and boiled in gel sample buffer.

SDS - polyacrylamide gels and detection of PTPase activity within gels. The 10 and $12.5 \%$ polyacrylamide-SDS gels were run according to the procedure of Laemmli (15), except the separating gel contained 0.13 and $0.10 \%$ bisacrylamide, respectively. Acrylamide, bisacrylamide, and the polymerizing reagents were from Bio-Rad (Richmond, CA). For detection of PTPase activity in SDS-polyacrylamide gels, ${ }^{32} \mathrm{P}$-labeled poly(glu:tyr) was incorporated into the regular polyacrylamide gel mix prior to polymerization at approx $10^{5} \mathrm{cpm} / \mathrm{ml}$. Following electrophoresis, all incubations were performed at room temperature on a shaker. The volume used for each incubation was about 250 $\mathrm{ml}$. Gels were first incubated in $50 \mathrm{~mm}$ Tris- $\mathrm{Cl}, \mathrm{pH}$ 8.0 , containing $20 \%$ isopropanol for either $1.5 \mathrm{~h}$ or overnight to remove the SDS. Gels were washed twice for 30 min each in $50 \mathrm{~mm}$ Tris- $\mathrm{Cl}$, pH 8.0, containing $0.3 \%$ $\beta$-mercaptoethanol, and then incubated in the same buffer containing $6 \mathrm{~m}$ guanidine hydrochloride and 1 mM EDTA for $90 \mathrm{~min}$. The gels were then incubated 
three times for $1 \mathrm{~h}$ each in renaturation buffer, $1 \mathrm{~mm}$ EDTA, 50 mM Tris- $\mathrm{Cl}$, pH 8.0, 0.3\% $\beta$-mercaptoethanol, $0.04 \%$ Tween 40 . The gels were finally incubated overnight in renaturation buffer containing $4 \mathrm{~mm}$ dithiothreitol. Following this incubation the gel was stained with Coomassie brilliant blue and destained as for a normal SDS-polyacrylamide gel and dried for autoradiography. Gels were exposed to Xomat film (Kodak) with an intensifying screen at room temperature or $-70^{\circ} \mathrm{C}$ for $24 \mathrm{~h}$ or longer as required.

Preparation of [ $\left.{ }^{32} \mathrm{P}\right]$ poly(glu:tyr). Briefly, $1 \mathrm{mg}$ of poly(glu:tyr) was incubated with $50 \mu$ l of a $20 \%$ suspension of a recombinant tyrosine kinase catalytic domain (GST - FER) (26, Huckle and Earp, unpublished observations), immobilized on agarose beads, kindly provided by Dr. S. Earp, in $0.5 \mathrm{~mL}$ kinase buffer $(30 \mathrm{~mm}$ $\mathrm{MgCl}_{2}, 1 \mathrm{~mm} \mathrm{MnCl}_{2}, 1 \mathrm{~mm}$ sodium orthovanadate, 0.2 or $1 \mathrm{~mm}$ ATP, $10 \mathrm{~mm}$ dithiothreitol, 0.05\% Triton $X$ 100, $50 \mathrm{~mm}$ imidazole, $\mathrm{pH}$ 7.2) to which 200-500 $\mu \mathrm{Ci}$ of $\left[\gamma-{ }^{32} \mathrm{P}\right]$ ATP $(3000 \mathrm{Ci} / \mathrm{mmol}$ ) (New England Nuclear) had been added. The kinase reaction was allowed to proceed with rotation at room temperature for $18 \mathrm{~h}$. The kinase reaction was terminated by sedimentation of the agarose beads and addition of an equal volume of $20 \%$ trichloracetic acid. After $30 \mathrm{~min}$ on ice, the precipitated poly(glu:tyr) was sedimented at $12,000 \mathrm{~g}$ for $10 \mathrm{~min}$ at $4^{\circ} \mathrm{C}$. The pellet was dissolved in $100 \mu \mathrm{l}$ of 2 M Tris- base, passed over a $15 \times 0.7-c m$ G50 Sephadex (Pharmacia) column equilibrated in $50 \mathrm{~mm}$ imidazole, $\mathrm{pH} 7.2$, and collected in 0.8-ml fractions. Incorporation of ${ }^{32} \mathrm{P}$ was measured by scintillation counting. Specific activities of between 0.7 and $3 \times 10^{8} \mathrm{cpm} / \mathrm{mg}(80-130$ $\mathrm{nmol}$ of phosphate per milligram) of poly(glu:tyr) was obtained.

F or some experiments poly(glu:tyr) was labeled with ${ }^{32} \mathrm{P}$ using the EGF receptor in crude A431 cell membranes as a kinase. The kinase reaction was performed using $1 \mathrm{mg}$ of poly(glu:tyr) in $0.5 \mathrm{ml}$ in $150 \mathrm{~mm} \mathrm{NaCl}$, $2 \mathrm{mM} \mathrm{MnCl}_{2}, 0.02 \%$ Triton X-100, 5\% glycerol, $0.1 \mathrm{~mm}$ sodium orthovanadate, $0.2 \mathrm{~mm}$ ATP, $50 \mathrm{~mm}$ Hepes, $\mathrm{pH}$ 7.4. To the kinase reaction were added $0.25 \mathrm{mCi}\left[{ }^{32} \mathrm{P}\right]$ ATP, $200 \mathrm{~nm} \mathrm{EGF,} \mathrm{and} 50 \mu \mathrm{l}$ of crude A431 cell membranes (a gift of Dr. Denis Alexander). The reaction was allowed to proceed with shaking at room temperature for 4-5 h. The membranes were sedimented in a microfuge for $1 \mathrm{~min}$ and to the supernatant was added an equal volume of $20 \%$ trichloracetic acid. The precipitated poly(glu:tyr) was then treated as described above. The [ $\left.{ }^{32} \mathrm{P}\right]$ poly(glu:tyr) had a specific activity of $\sim 3 \times$ $10^{7} \mathrm{cpm} / \mathrm{mg}$. Poly(glu:tyr) labeled in this way behaved identically when incorporated into gels and used to detect PTPase activity.

In one set of experiments poly(glu:tyr) was radioiodinated using $0.5 \mathrm{mCi} \mathrm{Na}{ }^{125}$ ( $\mathrm{New}$ England Nuclear) and iodogen (Pierce Co.) (16). A specific activity of $\sim 10^{9}$ cpm/mg poly(glu:tyr) was obtained.

\section{RESULTS}

In initial experiments, whole cell lysates were electrophoresed on SDS- gels containing [ $\left.{ }^{32} \mathrm{P}\right]$ poly(glu:tyr). It should be noted that during electrophoresis the [ $\left.{ }^{32} \mathrm{P}\right]$ poly(glu:tyr) did not migrate and that following el ectrophoresis little or no radioactivity was detected in the lower buffer chamber. The gels were processed in a variety of ways with the objective of removing the SDS and renaturing the proteins within the gel so that tyrosine phosphatase activity could be detected by release of ${ }^{32} \mathrm{P}$ from the substrate within the gel. Procedures used to detect kinases in gels $(13,14)$, were adapted. SDS was removed from the gel by washing in buffered isopropanol; the proteins were fully denatured in $6 \mathrm{M}$ guanidine hydrochloride and then gently renatured in buffers containing nonionic detergents and an excess of reducing agents. Using this approach, we were able to detect apparent PTPase activity in SDS- gels. Conditions were explored to optimizethe assay and its convenience. These included the time and temperature of renaturation, the ionic strength of the renaturing buffer, the need for the guanidine denaturation step, and the presence or absence of different detergents. The conditions that we settled on and have used for the assays in this work are given under Materials and Methods. It should be noted, however, that renaturation buffers containing other nonionic detergents in addition to Tween 40 (e.g., 1\% Triton X-100, 3\% NP$40,1 \%$ Brij 96 ) have given satisfactory renaturation of PTPase activity. In addition, we have found that significant renaturation of PTPase activity is detected when the guanidine step is omitted, although for many PTPases optimal renaturation has been observed when this is included.

Several experiments were performed to determine whether the removal of ${ }^{32} \mathrm{P}$ from the substrate in the gel was due to the activity of PTPases. In one set of experiments, a series of gel slices with parallel loadings of whole rat embryo fibroblasts (REF52) and human platelets was processed in different ways. One gel slice was treated as described under Materials and Methods to detect PTPases, with incubation in renaturation buffers being for a total of $6 \mathrm{~h}$ (Fig. 1, left). A second slice, following the guanidine denaturation step, was incubated for the same time period but in renaturation buffers containing $10 \mathrm{~mm}$ sodium orthovanadate (Fig 1 , middle). This greatly diminished the removal of ${ }^{32} \mathrm{P}$ from the gel. A third slice was treated identically to the first slice, except reducing agents were omitted from all buffers following el ectrophoresis. This abol ished the removal of ${ }^{32} \mathrm{P}$ from the substrate. The removal of ${ }^{32} \mathrm{P}$ from the gel could also arise from proteolytic digestion of the substrate. To explore whether this might be occurring, we labeled the poly(glu:tyr) with ${ }^{125} \mathrm{I}$, and included this in a gel in which several whole cell lysates 


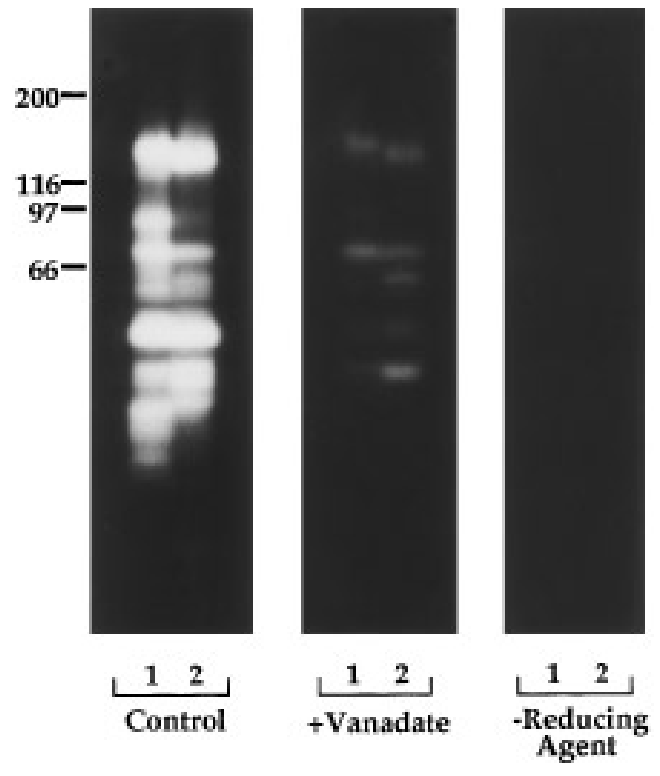

FIG. 1. Renaturation of PTPase activity in SDS-polyacrylamide gels. Twenty micrograms of protein of rat embryo fibroblasts (RE F 52) (lanes 1) or human platelets (lanes 2) was electrophoresed on a $10 \%$ polyacrylamide gel containing $\left[{ }^{32} \mathrm{P}\right]$ poly(glu:tyr). Following electrophoresis, the gel was sliced and pairs of lanes processed separately. The first pair of lanes (control) was treated as described under Materials and Methods to renature PTPase activity. I ncubation in renaturation buffers was for a total of $6 \mathrm{~h}$. The second pair of lanes (+ vanadate) was processed identically, except $10 \mathrm{~mm}$ sodium orthovanadate was included in all the renaturation buffers. The third pair of lanes (-reducing agent) was treated as for the control samples, except that following electrophoresis reducing agents were omitted from all subsequent buffers. Following processing, the gels were dried down and the autoradiographs are shown. Numbers on the left correspond to the positions of migration of proteins of known molecular weight: myosin $(200,000), \beta$-galactosidase $(116,000)$, phosphorylase $(97,000)$, and bovine serum albumin $(66,000)$. Note that PTPase activity is detected in multiple bands in the control samples, but is greatly reduced by the inclusion of vanadate and is not detected in the absence of reducing agents.

were electrophoresed. The gel was processed as for the ${ }^{32} \mathrm{P}$ substrate-containing gels. Autoradiography revealed uniform distribution of the ${ }^{125}$ substrate (data not shown). No "cleared" bands were detected, indicating that proteolysis was not accounting for the removal of the substrate from the gels. Other ${ }^{32} \mathrm{P}$-labeled substrates were explored. Low-molecular-weight ${ }^{32} \mathrm{P}$-labeled peptides, such as angiotensin, were not retained in the gel during electrophoresis. Labeled protein substrates were tested in preliminary experiments but suffered the potential disadvantage that they may be susceptible to proteolysis within the gel due to the activity of renatured proteases. In addition, poly(glu:tyr) was found to be the easiest substrate to label to a high specific activity. No difference was found when the poly(glu:tyr) was labeled with two different kinases.

Two known PTPases, PTP1D and PTP1B, were im- munoprecipitated from src-transformed rat cells or from rat embryo fibroblasts, respectively. These immunoprecipitates and the corresponding whole cell lysates were electrophoresed on gels containing [ $\left.{ }^{32} \mathrm{P}\right]$ poly(glu:tyr) (Fig. 2). Multiple bands were detected in the samples of whole cells and a major band of activity was detected in each immunoprecipitate. In the case of PTP1B, the activity had an apparent molecular mass of $\sim 50,000$, and with PTP1D, the activity was at about 70,000 . These correspond to the published molecular masses of these PTPases (17-19) and relate to major bands of activity seen in the whole cell lysates. With PTP1D a second band of activity was consistently detected at about 60,000 . This may be due to proteolytic degradation, although it may indicate a second PTPase associated with PTP1D. Multiple minor bands of PTPase activity were seen in the PTP1B immunoprecipitates. These were always lower than the PTP1B band and varied in different experiments, suggesting that they may be proteolytic degradation products.

To expl ore the sensitivity of the assay, known concentrations of several phosphatases were run on gels containing [ $\left.{ }^{32} \mathrm{P}\right]$ poly(glu:tyr). These included PTP 1 (the rat homolog of PTP1B), the Yersinia PTPase, a dual specificity phosphatase $\mathrm{VH} 6$, and alkaline phosphatase.
A

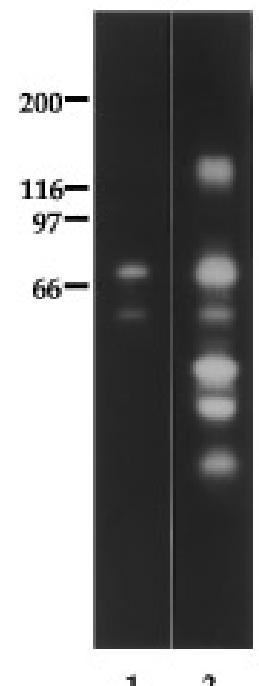

12
B

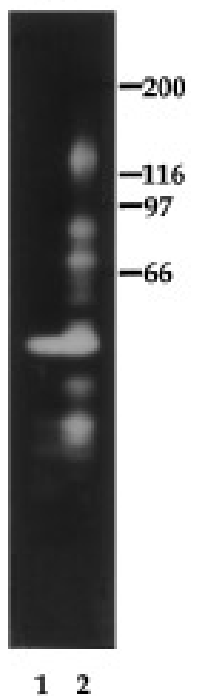

12
FIG. 2. Detection of PTPID and PTP1B in SDS-polyacrylamide gels. Autoradiographs are shown of gels processed for PTPase detection. PTP1D was immunoprecipitated (A, lane 1$)$ from RR 1022 cells (A, lane 2). PTP1B was immunoprecipitated (B, lane 1 ) from REF 52 cells ( $B$, lane 2). I mmunoprecipitates were prepared as described under Materials and Methods. I mmunoprecipitates and whole cell Iysates $(20 \mu \mathrm{g})$ were electrophoresed on separate gels containing $\left.{ }^{32} \mathrm{P}\right]$ poly(glu:tyr). Numbers on each side correspond to the positions of migration of proteins of known molecular weight: myosin $(200,000), \beta$-galactosidase $(116,000)$, phosphorylase $(97,000)$, and bovine serum albumin $(66,000)$. 


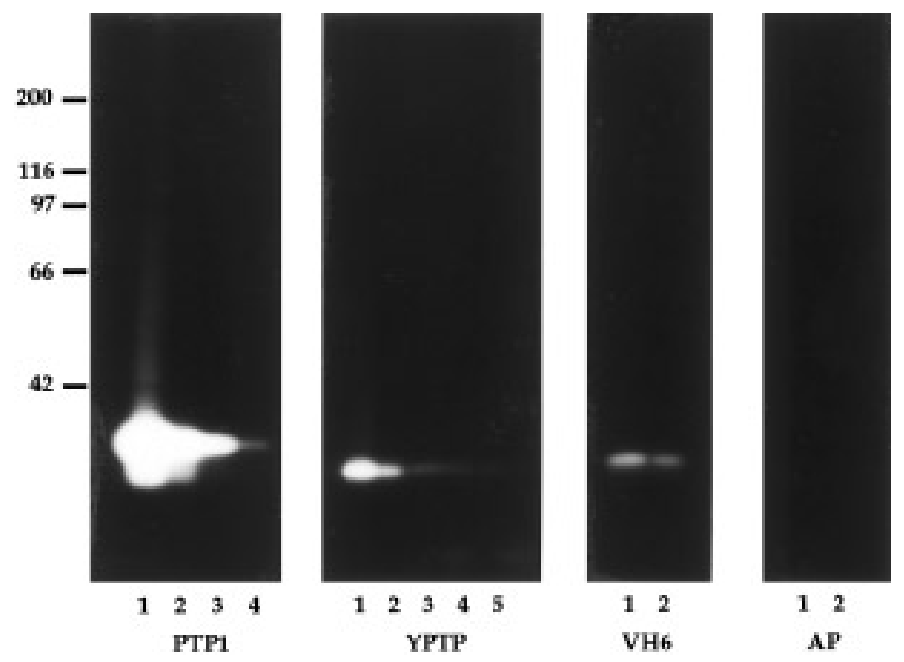

FIG. 3. Analysis of known phosphatases in SDS-polyacrylamide gels. Four phosphatases, PTP1, the Yersinia PTPase (YPTP), the dual specificity phosphatase (VH6), and alkaline phosphatase (AP), were electrophoresed at various concentrations on $10 \%$ polyacrylamide gels containing $\left[{ }^{32} \mathrm{P}\right]$ poly (glu:tyr) and processed to detect phosphatase activity. The protein loadings for PTP1 were $10 \mathrm{ng}$ (lane 1), 1 ng (lane 2), 100 pg (lane 3), and 10 pg (lane 4). For the Yersinia PTPase (YPTP), the loadings were 100 pg (lane 1), 25 pg (lane 2), 10 pg (lane 3), 2.5 pg (lane 4), and 1 pg (lane 5). For the dual specificity phosphatase VH6, the loadings were $1 \mu \mathrm{g}$ (lane 1) and $0.5 \mu \mathrm{g}$ (lane 2). For alkaline phosphatase (AP) the loadings were $1 \mu \mathrm{g}$ (lane 1) and $0.5 \mu \mathrm{g}$ (lane 2). Numbers on the left side of the autoradiograph correspond to the positions of migration of proteins of known molecular weight: myosin $(200,000), \beta$-galactosidase $(116,000)$, phosphorylase $(97,000)$, bovine serum albumin $(66,000)$, and ovalbumin $(42,000)$.

These were analyzed over a very wide range of protein concentrations (Fig. 3, and data not shown). PTP1 and the Yersinia PTPase were both detected at levels as low as 10 pg of protein loaded in a gel lane (Fig. 3). In some experiments the Yersinia PTPase was detected at $2.5 \mathrm{pg}$ of protein. In contrast, the VH6 dual-specificity PTPase was only detected at high concentrations of protein (above $100 \mathrm{ng}$ ). Alkaline phosphatase was not detected in the assay even when $1 \mu \mathrm{g}$ of protein was loaded on a gel. A serine/threonine phosphatase, PP2A, was examined following immunoprecipitation from cells, but no removal of ${ }^{32} \mathrm{P}$ from the labeled poly(glu:tyr) was detected when these immunoprecipitates were analyzed in gels (data not shown). I mmunopreci pitates were also analyzed of CD45, a major transmembrane PTPase found in many leukocytes. No activity was detected for CD45 using this in-gel assay (data not shown). However, a cytoplasmic domain construct of CD45 did reveal activity when loaded at very high concentrations on gels ( $1 \mu \mathrm{g}$ or higher) (data not shown).

The sensitivity of the in-gel assay should depend on the time of incubation of the gel under conditions allowing renaturation of PTPases. The dependence on time for the assay was explored by varying the length of time of the final incubation from 1 to $20 \mathrm{~h}$ using parallel gel slices on which three different concentrations of PTP 1 had been electrophoresed (Fig. 4). I ncubation for just $1 \mathrm{~h}$ in the final buffer (following $3 \times 1$ $\mathrm{h}$ washes in renaturation buffer) resulted in significant detection of PTPase activity (Fig. 4A). The sensitivity was increased by increasing the incubation to $6 \mathrm{~h}$ (Fig. $4 \mathrm{~B})$, but with a further increase in incubation to $20 \mathrm{~h}$ the additional gain in sensitivity was very small (Fig. 4C). For most purposes $6 \mathrm{~h}$ of incubation should be sufficient.

We wished to examine the profile of PTPases in different tissues and cells using this in-gel assay. Several tissues (brain, liver, gizzard, breast muscle, and heart) were isolated from 12- and 20-day chicken embryos. These were dissolved in gel sample buffer and equal protein concentrations were run on a gel containing the ${ }^{32} \mathrm{P}$ substrate and then processed for detection of PTPase activity (data not shown). The profiles of PTPase activity detected in this gel indicated surprising similarity between the samples, with each reveal-

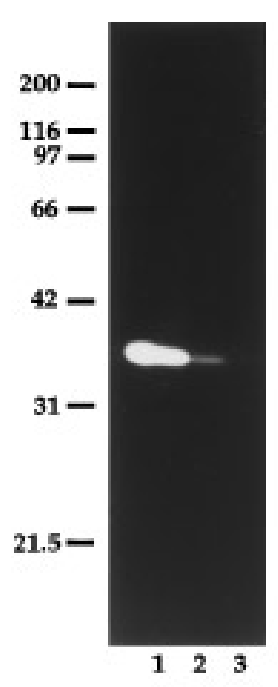

A
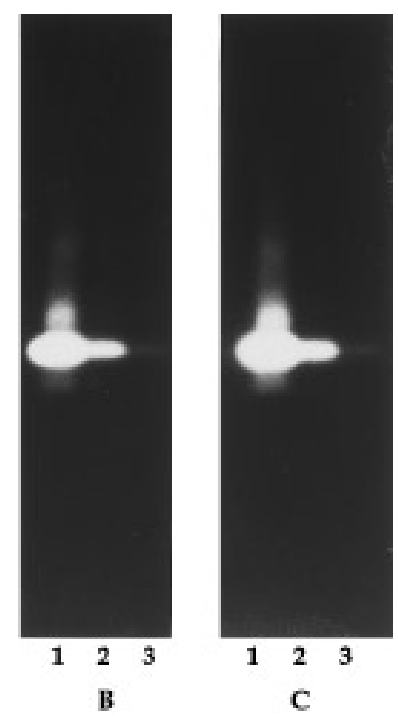

FIG. 4. Analysis of the effect of time of renaturation on the sensitivity of detection of phosphatase activity within gels. PTP 1 was electrophoresed at three different protein loadings on parallel lanes of a $12.5 \%$ polyacrylamide gel containing $\left.{ }^{32} \mathrm{P}\right]$ poly(glu:tyr). One nanogram of PTP1 was run in lane $1,100 \mathrm{pg}$ in lane 2, and $10 \mathrm{pg}$ in lane 3. Gel slices A, B, and C were processed identically including $3 \times 1$ $h$ washes in renaturation buffer. The final (fourth) incubation in renaturation buffer was varied. A was incubated for $1 \mathrm{~h}$ before fixing and staining. B was incubated for $6 \mathrm{~h}$. C was incubated for $20 \mathrm{~h}$. Note that the sensitivity of detection increased significantly going from the 1-h final incubation to $6 \mathrm{~h}$, but there is less effect extending this incubation to $20 \mathrm{~h}$. Numbers on the left side of the autoradiograph correspond to the positions of migration of proteins of known molecular weight: myosin $(200,000), \beta$-galactosidase $(116,000)$, phosphorylase $(97,000)$, bovine serum albumin $(66,000)$, ovalbumin $(42,000)$, and carbonic anhydrase $(31,000)$. 

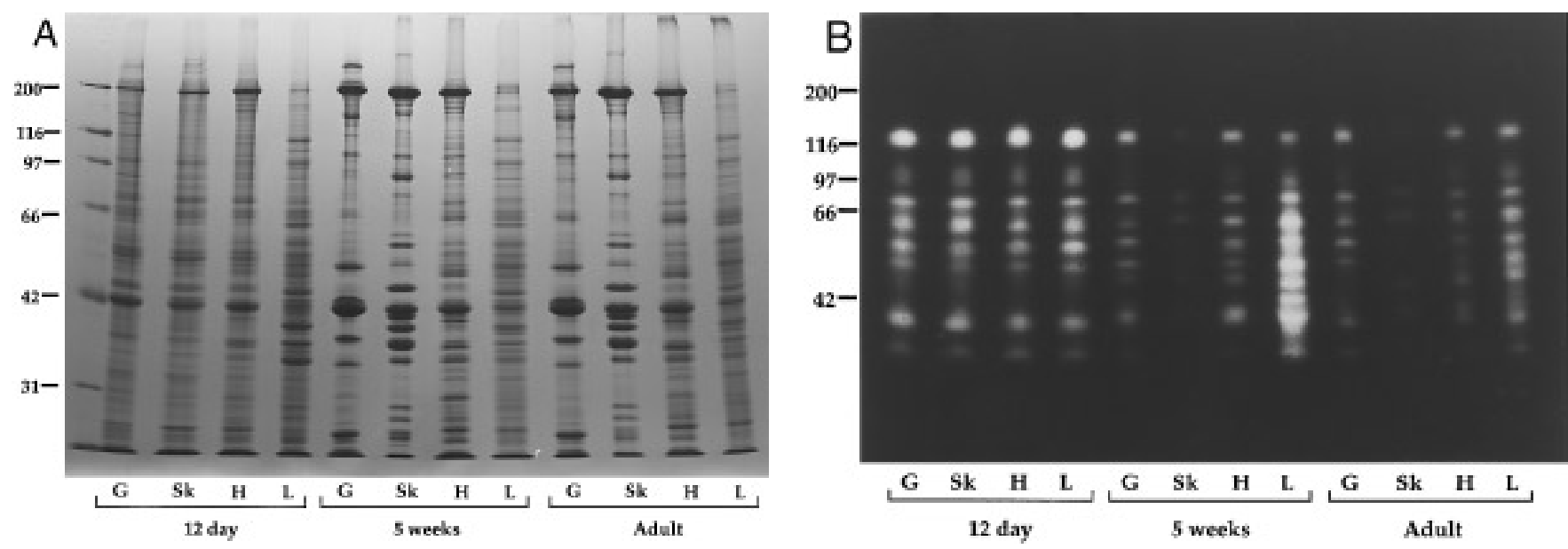

FIG. 5. Gel analysis of proteins and PTPase activity in samples of different chicken tissues. Tissues from 12-day embryos or 5-week-old or adult chickens were dissected and dissolved in SDS. After protein determination, equal amounts of protein (20 $\mu \mathrm{g}$ ) were electrophoresed either on a regular $10 \%$ polyacrylamide gel, which was then stained with Coomassie blue (A), or on a 10\% polyacrylamide gel containing $\left[{ }^{32} \mathrm{P}\right]$ poly(glu:tyr), which was processed to detect PTPase activity. Numbers on the left of the gel and autoradiograph correspond to the positions of migration of proteins of known molecular weight: myosin $(200,000)$, $\beta$-galactosidase $(116,000)$, phosphorylase $(97,000)$, bovine serum albumin $(66,000)$, ovalbumin $(42,000)$, and carbonic anhydrase $(31,000)$.

ing 7- 8 major bands, ranging in $M_{r}$ from about 130,000 to 30,000 . Minor differences between the samples were detectable, but these were mainly in the intensity of specific bands, rather than the absence or presence of bands. We considered that the similarity between the profiles of the different tissues might reflect the fact that all the tissues were embryonic and growing rapidly. To address this, we compared the pattern of PTPase activity in samples of four tissues (gizzard, breast skeletal muscle, heart, and liver) from 12-day embryos and 5-week-old and adult chickens (Fig. 5). For comparison and to confirm equal loading of protein, a parallel gel of the same samples was stained for protein (Fig. 5A). In this analysis of PTPase activity, the embryonic tissues did, indeed, show higher levels of activity than the more mature tissues, with the exception of liver. At 5 weeks following hatching, the liver sample showed the highest PTPase activity and this remained relatively high in the adult sample compared with the profile of PTPases in the other tissues examined. By contrast, the skel etal muscle samples showed greatly diminished PTPase activity in the samples of 5 week and adult tissues. A decrease in activity was al so seen in the gizzard and heart samples. Despite the decreased activity, short exposure of the autoradiographs (to increase the sensitivity of detection) indicated that essentially the same profile of PTPase bands was seen in these tissues at these different stages of development (data not shown). This suggested that the same PTPases were being expressed in the embryonic and adult tissues, but that the level of expression was being modulated in some tissues.

The chicken tissues analyzed above contained het- erogeneous cell populations and we were curious about the distribution of PTPases in individual cell types. For this analysis we obtained cells from human sources, including erythrocytes, platelets, monocytes, peripheral blood lymphocytes, and sperm. Examining isol ated cell types indicated greater variation in the pattern of PTPase bands revealed in gels than did the analysis of whole tissues (Fig. 6). Some of the most differentiated cell types, such as erythrocytes and sperm, were distinctive. In erythrocytes, the activity was concentrated in two bands, at about 70 and $55 \mathrm{kDa}$. The level of activity was low and about 10 times the amount of protein was loaded on the gel compared with the other samples. Similarly, the level of cytoplasmic PTPases in sperm was low, but three distinct bands were seen when the autoradiograph was exposed for a short time. These bands were at about 130, 62, and $50 \mathrm{kDa}$. Platelets, monocytes, and lymphocytes all reveal ed generally similar patterns of PTPase bands, running at approximately 130, 95, 70, 62, 50, 46, and $42 \mathrm{kDa}$.

Several cell lines were also examined for their profile of cytoplasmic PTPases using this in-gel assay (Fig. 7). These cell lines all showed very similar patterns of PTPase bands, with only slight differences such as relatively lower levels of the 130-kDa PTPase band in Raji cells compared with the prominence of this band in the other cell types analyzed.

\section{DISCUSSION}

In this paper we have developed an assay to detect PTPases directly in SDS- polyacrylamide gels. Several lines of evidence indicate that we are detecting PTPase 


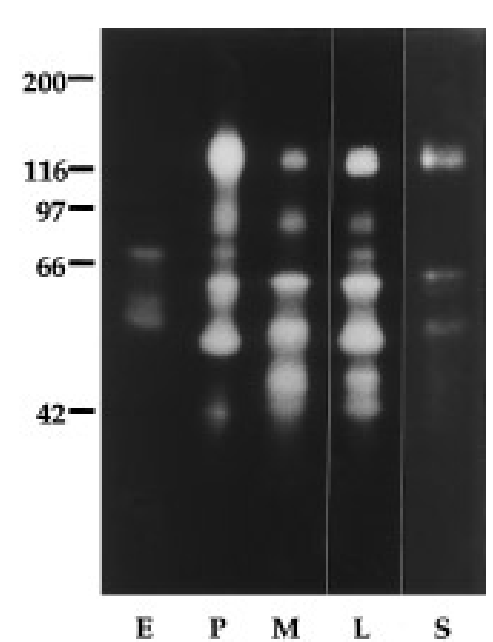

FIG. 6. Gel analysis of PTPase activity in samples of different human cell types. Samples of erythrocytes $(E)$, platelets $(P)$, monocytes (M), peripheral blood lymphocytes (L), and spermatozoa (S) were electrophoresed on a $10 \%$ polyacrylamide gel containing $\left[{ }^{32} \mathrm{P}\right]$ poly(glu:tyr). Approximately $20 \mu \mathrm{g}$ of protein was run in each lane, except for the erythrocyte sample which was 10 times higher. Following electrophoresis, the gel was processed to detect PTPase activity. The lane corresponding to the sperm sample was exposed for autoradiography for a shorter time so that the relatively faint bands could be more readily detected. Numbers on the left of the autoradiograph correspond to the positions of migration of proteins of known molecuIar weight: myosin $(200,000)$, $\beta$-galactosidase $(116,000)$, phosphorylase $(97,000)$, bovine serum albumin $(66,000)$, and ovalbumin $(42,000)$

activity. For example, known PTPases generate bands with the expected apparent molecular weight. The activity is inhibited by inhibitors of PTPases such as sodium orthovanadate and the activity requires reduced sulfhydryls, a characteristic of the catalytic site of PTPases (4). Furthermore, when the substrate, $\left[{ }^{32} \mathrm{P}\right]-$ poly(glu:tyr) is replaced with [ ${ }^{125} \mid$ ]poly(glu:tyr), no removal of ${ }^{125}$ is detected, indicating that the removal of ${ }^{32} \mathrm{P}$ is not simply due to proteolysis. One advantage of using $\left[{ }^{32} \mathrm{P}\right]$ poly(glu:tyr) as a substrate is that it appears to be relatively resistant to proteolytic digestion. This may not be the case with other potential substrate proteins, which could result in the appearance of PTPase activity that was really due to proteolysis. We have also found that $\left[{ }^{32} \mathrm{P}\right]$ poly(glu:tyr) is well retained in the gel during electrophoresis, whereas low-molecularweight, ${ }^{32} \mathrm{P}$-labeled peptides are not. Another advantage of $\left[{ }^{32} \mathrm{P}\right]$ poly(glu:tyr) is that it is easily labeled by different tyrosine kinases and its use in the assay does not appear to be affected by the kinase used to label it. As suggested by one referee of this paper, substituting ${ }^{33} \mathrm{P}$ for ${ }^{32} \mathrm{P}$ should enhance the clarity of the bands of PTPase activity detected in this assay, due to the lower energy of the $\beta$ particles emitted by ${ }^{33} \mathrm{P}$.

The ease of detecting PTPases in this in-gel assay would be expected to vary for different PTPases and to reflect such factors as the intrinsic activity of the PTPase to the substrate in the gel and the degree of renaturation of the PTPase. For some PTPases, [ $\left.{ }^{32} \mathrm{P}\right]-$ poly(glu:tyr) may be a poor substrate. This is probably true for the mixed specificity phosphatases, such as VH6, that was only detectable in the in-gel assay at levels of about $1 \mu \mathrm{g}$ of protein. For some of the cytoplasmic PTPases (e.g., PTP 1 and the Yersinia PTPase), we have detected levels as low as $10 \mathrm{pg}$ of purified PTPase. This probably reflects both a high intrinsic enzymatic activity of these PTPases using [ $\left.{ }^{32} \mathrm{P}\right]-$ poly(glu:tyr) as a substrate and efficient renaturation in the gel. In preliminary experiments, we examined the renaturation of PTP1 in solution, after denaturation in SDS. A total of $10-30 \%$ of the starting activity was recovered following renaturation in the buffers used for processing the gels (data not shown).

Using the in-gel assay, we have not been able to detect activity in immunoprecipitates of members of the transmembrane group of PTPases, such as CD45. In addition, we have not detected high-molecular-weight PTPases above $130 \mathrm{kDa}$ in lymphocytes or in any other whole cell lysates, except in endothelial cells (Fig. 7). Most of the transmembrane family of PTPases, like CD45, are above $130 \mathrm{kDa}(3-5)$ and this strongly suggests that our conditions do not effectively renature

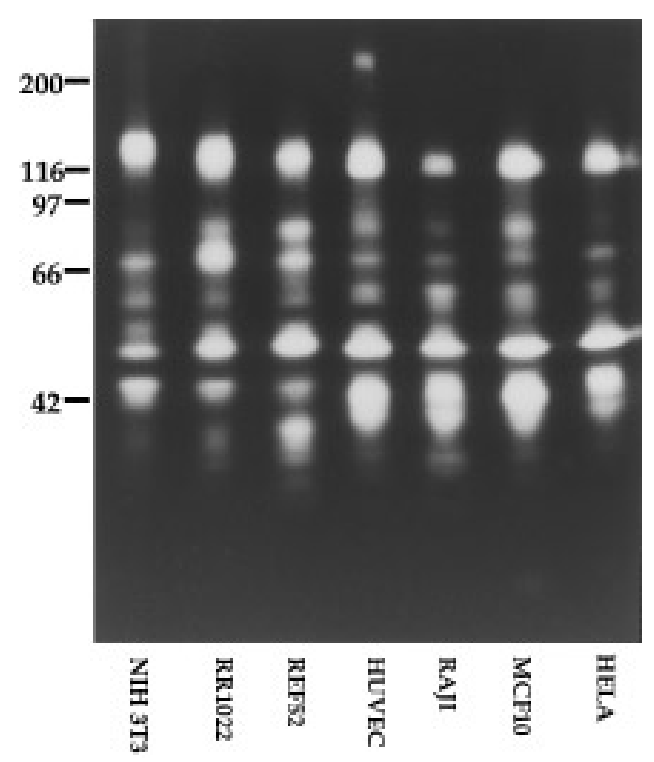

FIG. 7. Gel analysis of PTPase activity in samples of different cell lines. Various cultured cell lines were dissolved in SDS and equal amounts of protein $(20 \mu \mathrm{g})$ electrophoresed on a $10 \%$ polyacrylamide gel containing $\left.{ }^{32} \mathrm{P}\right]$ poly(glu:tyr). Following electrophoresis, the gel was processed to detect PTPase activity. The names of the different cell lines are indicated below the autoradiograph. Numbers on the left of the autoradiograph correspond to the positions of migration of proteins of known molecular weight: myosin $(200,000), \beta$-galactosidase $(116,000)$, phosphorylase $(97,000)$, bovine serum albumin $(66,000)$, and ovalbumin $(42,000)$. 
this group of PTPases. Several features distinguish the transmembrane PTPases from the cytoplasmic PTPases and may contribute to their poor renaturation. These characteristics include the hydrophobic transmembrane domain, the disulfide-bonded extracelIular domain, and the existence of two potential cataIytic domains arranged in tandem within the cytoplasmic sequence of most transmembrane PTPases. In preliminary work, we have investigated the activity of a recombinant fragment of CD45, lacking the extracellular and transmembrane domains. This bacterially expressed protein exhibited high PTPase activity on [ $\left.{ }^{32} \mathrm{P}\right]-$ poly(glu:tyr) in solution assays, but was only detected at very high sample loadings $(1 \mu \mathrm{g})$ in the in-gel assay. Similarly, a recombinant protein containing the cytoplasmic domain of the transmembrane PTPase, PTP $\alpha$, was only detectable in gels when loaded at the microgram level. Because these fragments lacked extracellular and transmembrane domains, the low activity in the assay cannot be ascribed to a failure of these domains to renature. These findings suggest that the tandem PTPase motifs may in some way affect the renaturation of activity. The reason for the two PTPase domains in the transmembrane PTPases has not been established. For CD45 the majority of evidence indicates that the membrane proximal PTPase domain is responsible for catalytic activity, whereas the second domain appears to be inactive $(20,21)$, although under some circumstances activity has been identified in both domains (22). Some mutations in the second domain or truncation of the spacer region separating the two domains render CD45 catalytically inactive (23). One interpretation of these results is that the second domain or its conformation regulates the activity of the first domain. If the second domain does regulate the activity of the first domain, or if the activity is dependent on the precise renaturation of both domains, then this may impose a stringent requirement for both domains to renature fully in order for activity to be detected with these transmembrane PTPases in the ingel assay. In future experiments, we wish to explore other conditions that will promote renaturation of the transmembrane PTPase and thereby allow their identification in SDS-gels.

Using this in-gel PTPase assay, we have examined the profile of PTPases expressed in a variety of tissues and cells. All cells and tissues examined expressed multiple PTPases detectable in this assay. The striking observation is how similar the pattern of PTPases is in most cell types. Many PTPases seem to be widely distributed. Only in the very terminally differentiated cells, such as erythrocytes and sperm, was the profile distinct. Erythrocytes revealed the most unusual pattern and it may be that their PTPases remain from earlier in the life history of these cells when tyrosine kinases were probably important in the growth and differentiation of erythrocyte precursors. A transmembrane tyrosine kinase has been identified in mammalian sperm that becomes activated in response to sperm-zona pellucida binding (24). This is an important early step in fertilization that leads to release of the acrosome. Given the presence of tyrosine kinases in sperm, one would expect these to be accompanied by PTPases. Our analysis here indicates the presence of at least three cytoplasmic PTPases in sperm, albeit at lower levels than in many other cell types. It will be interesting in future work to determine whether these are colocalized with the tyrosine kinase in sperm.

For most of the cell types and tissues we have examined, the profile of cytoplasmic PTPases has been unexpectedly constant. Of course, a band of activity from two different cell types cannot be said to be the same PTPase without further identification. Nevertheless, the similarity in the patterns of PTPase activity does suggest that in most cells many of the same PTPases are being expressed. Two of the bands that are prominent in many cells we have tentatively identified as PTP1B and PTP1D. One of the other prominent bands, seen in most cell types is at $\sim 120-130 \mathrm{kDa}$. This may correspond to the recently identified PTPD1 (25), given the fact that PTPD1 is reported to be widely distributed (25). In addition, we have shown that the PTPase responsible for most if not all of this activity at $130 \mathrm{kD}$ is itself tyrosine phosphorylated in src-transformed cells (our unpublished results), a characteristic of PTPD1 (25).

The detection of PTPases directly in gels has several advantages. The analysis provides an indication of apparent subunit mass of the detected PTPase. The assay permits analysis of PTPases in very crude samples, such as whole cell lysates or subcellular fractions. In addition, the technique should be useful for analyzing the association of PTPases with other components, such as kinases or other signaling proteins, that have been isolated from cells by immunoprecipitation or other means.

\section{ACKNOWLEDGMENTS}

We are most grateful to Drs. J ack Dixon and Daniel Lohse who generously provided purified PTP1, Yersinia PTPase, and the dual specificity phosphatase, VH6. We thank Dr. S. Earp for generously providing the GST - FER construct used in this work. We thank Drs. Michael Kinch, J ulie Frearson, and Galen Schneider for valuable discussions and many of our colleagues for advice and for providing various cell types and samples. Dr. Susanne Bockholt provided help and advice with the figures. Some final experiments and much of the writing of the paper were performed while one of us (K.B.) was on sabbatical in the laboratory of Dr. Denis Alexander at the Babraham Institute, Cambridge, UK. K.B. thanks Denis Alexander for his generous hospitality, gifts of recombinant CD45 constructs and his comments on the manuscript. While on sabbatical, K.B. was supported by a Kenan Leave, which is gratefully acknowledged. The work was supported by NIH Grants GM29860 and HL 45100. 


\section{REFERENCES}

1. Fantl, W. J ., J ohnson, D. E., and Williams, L. T. (1993) Annu. Rev. Biochem. 62, 453- 481.

2. Van der Geer, P., Hunter, T., and Lindberg, R. A. (1994) Annu. Rev. Cell Biol. 10, 251-337.

3. Tonks, N. K., Flint, A. J ., Gebbink, M. F. B. G., Sun, H., and Yang, Q. (1993) Adv. Second Messenger Phosphoprotein Res. 28, 203-210.

4. Walton, K. M., and Dixon, J . E. (1993) Annu. Rev. Biochem. 62, 101- 120.

5. Mourey, R. J ., and Dixon, J. E. (1994) Curr. Opin. Gen. Dev. 4, 31- 39.

6. Heeb, M. J ., and Gabriel, O. (1984) Methods Enzymol. 104, 416439.

7. Heussen, C., and Dowdle, E. B. (1980) Anal. Biochem. 102, 196202.

8. Miskin, R., and Soreq, H. (1981) Anal. Biochem. 118, 252- 258.

9. Chin, J . R., Murphy, G., and Werb, Z. (1985) J . Biol. Chem. 260, 12,367- 12376.

10. Herron, G. S., Werb, Z., Cwyer, K., and Banda, M. J . (1986) J . Biol. Chem. 261, 2814-2818.

11. Unemori, E. L., Bouhana, S., and Werb, Z. (1990) J . Biol. Chem. 265, 445-451.

12. Irvine, J. W., Roberts, S. F., and Lindberg, I. (1990) Anal. Biochem. 190, 141- 146.
13. Kameshita, I., and Fujisawa, H. (1989) Anal. Biochem. 183, 139 143.

14. Gotoh, Y., Nishida, E., Yamashita, T., Hoshi, M., Kawakami, M., and Sakai, H. (1990) FEBS Lett. 337, 200-206.

15. Laemmli, U.K. (1970) Nature 227, 680-685.

16. Fraker, P. J ., and Speck, J. C. (1978) Biochem. Biophys. Res. Commun. 80, 849- 857.

17. Frangione, J . V., Beahm, P. H., Shifrin, V., J ost, C. A., and Neel, B. G. (1992) Cell 68, 545-560.

18. Freeman, R. M., Plutzky, J ., and Neel, B. G. (1992) Proc. Natl. Acad. Sci. USA 89, 11239- 11243.

19. Vogel, W., Lammers, R., Huang, J ., and Ullrich, A. (1993) Science 259, 1611- 1614.

20. Streuli, M., Kreuger, N. X., Tsai, A. Y. M., and Saito, H. (1990) Proc. Natl. Acad. Sci. USA 86, 8698- 8702.

21. Streuli, M., Kreuger, N. X., Thai, T., Tang, M., and Saito, H. (1990) EMBO J . 9, 2399-2407.

22. Tan, X., Stover, D. R., and Walsh, K. A. (1993) J . Biol. Chem. 268, 6835- 6838 .

23. Ng, D. H. W., Miati, A., and J ohnson, P. (1995) Biochem. Biophys. Res. Commun. 206, 302- 309.

24. Burks, D. J ., Carballada, R., Moore, H. D. M., and Saling, P. M. (1995) Science 269, 83- 86.

25. Moller, N. P. H., Moller, K. B., Lammers, N., Kharitonenkov, A., Sures, I., and Ullrich, A. (1994) Proc. Natl. Acad. Sci. USA 91, 7477-7481.

26. Hao, Q-L, Heisterkamp, N., and Groffen, J . (1989) Mol. Cell. Biol. 9, 1587- 1593. 